\title{
The relationship between DNA methylation and Reprimo gene expression in gastric cancer cells
}

\author{
Junzhong Lai ${ }^{1, *}$, Hanze Wang ${ }^{1, *}$, Qianping Luo ${ }^{1}$, Shanlu Huang ${ }^{1}$, Shujin Lin ${ }^{1}$, \\ Yansong Zheng ${ }^{2}$ and Qi Chen ${ }^{1}$ \\ ${ }^{1}$ Fujian Key Laboratory of Innate Immune Biology, Biomedical Research Center of South China, College of Life Science, Fujian \\ Normal University Qishan Campus, Fuzhou, Fujian Province, China \\ ${ }^{2}$ The First Affiliated Hospital of Fujian Medical University, Fuzhou, Fujian Province, China \\ *These authors contributed equally to this work
}

Correspondence to: Qi Chen, email: nfsw@fjnu.edu.cn

Keywords: gastric cancer, reprimo, dna methylation, dna methyltransferase, zebularine

Received: December 12, $2016 \quad$ Accepted: September 13, $2017 \quad$ Published: September 28, 2017

Copyright: Lai et al. This is an open-access article distributed under the terms of the Creative Commons Attribution License 3.0 (CC BY 3.0), which permits unrestricted use, distribution, and reproduction in any medium, provided the original author and source are credited.

\section{ABSTRACT}

Reprimo (RPRM) is a tumor suppressor involved in the development of a number of malignant tumors including gastric cancer which is highly related to its gene hypermethylation. However, the regulation of RPRM gene expression by DNA methylation in gastric cancer is not well understood. We examined the RPRM gene methylation in gastric cancer tissues or plasma samples by bisulfite sequencing, and investigated the relationship between DNA methylation and the RPRM gene expression by quantitative reverse transcription-PCR and Western blotting. We found that the RPRM gene promoter region is hypermethylated in gastric cancer tissues (75\%, 45/60), plasma samples (86.3\%, 44/51) and various cancer cell lines $(75 \%, 3 / 4)$, which is correlated with the decrease of RPRM gene expression. The hypermethylation-induced RPRM reduction can be recovered by treating with zebularine, a demethylating agent, and by inhibition of the DNA methyltransferases via RNA interference and CRISPR/Cas9-mediated gene knockout. In addition, we generated RPRM gene-knockout cells and studied the effects of the RPRM deficiency on tumor formation by inoculating these cells in mice. The data show that the loss of RPRM can promote tumorigenesis. These data suggest that the RPRM expression is inhibited by DNA methyltransferases and the RPRM normal function can be restored by treating with DNA methylation inhibitors. The study provides important information regarding the role of RPRM and its methylation related to gastric cancer development.

\section{INTRODUCTION}

Gastric cancer is one of the leading causes of cancer-related death worldwide, and is highly prevalent in Asia, particularly in China [1, 2]. Despite recent progress in surgery and chemotherapy, the prognosis for gastric cancer is still not favorable. Therefore, early detection, better understanding of the molecular mechanisms and finding the new therapeutic strategies for this disease are imperative challenges [3]. Reprimo (RPRM), TP53 dependent G2 arrest mediator candidate, is a highly glycosylated protein and initially discovered as a putative tumor-suppressor involved in the regulation of p53dependent G2 arrest of the cell cycle [4, 5]. Aberrant methylation of RPRM gene is shown to be closely related to the occurrence and development of gastric cancer [4].

DNA methylation plays a critical role in gene regulation, cellular differentiation and embryonic development [6]. Aberrant DNA methylation can disrupt normal gene functions and lead to various disease pathogenesis [7]. In carcinogenesis, aberrant DNA methylation appears in various ways including hypermethylation of tumor suppressor genes, aberrant expression of DNA methyltransferases (DNMTs), as 
well as hypermethylation of selected genes and repetitive sequences [8]. To reactivate the tumor suppressor genes by demethylation is an attractive therapeutic strategy of epigenetic therapy in order to rehabilitate aberrant cells [9].

DNMTs are the key regulators of DNA methylation and have crucial roles in epigenetic modification $[10$, 11]. They transfer methyl groups from S-adenosyl methionine to the 5' unmethylated DNA cytosine ring to form 5-methylcytosine [12]. Three subtypes of DNMTs, including DNMT1, DNMT3A and DNMT3B, have been shown to have this activity, while the function of DNMT2 is currently unclear. DNMT1 is involved in maintaining DNA methylation by methylating newly synthesized strands of DNA during DNA replication [13, 14], whereas DNMT3A and DNMT3B are mainly involved in de novo methylation [15-20]. DNMT1 and DNMT3B have found to be overexpressed in gastric cancer [21].

DNA methyltransferase inhibitors 5-azacytidine and 5-aza-2-deoxycytidine have been developed, and used for treating myelodysplastic syndrome and acute myelogenous leukemia due to their abilities to reverse tumor suppressor gene methylation and restore gene expression $[8,22$, 23]. These inhibitors function as nucleoside analogues and inhibit DNMT activity through covalent binding to the DNMT enzymes [4, 6]. The use of these two drugs has been limited due to their toxicity, instability, and low efficacy. Zebularine (1-(b-D-ribofuranosyl)-1, 2-dihydropyrimidin-2-one) is a cell-permeable chemically stable cytidine analog that was initially discovered as a deaminase inhibitor [24-26]. Zebularine is thought to be a better DNA methyltransferase inhibitor due to its relative low toxicity, high stability, and oral bioavailability [24, 27-37].

In the present study, we examined the DNA methylation of the RPRM gene promoter region derived from the cancer tissues and blood samples of gastric cancer, evaluated the relationship between RPRM promoter methylation and its gene expression in several cancer cell lines. The role of DNMTs in regulating RPRM methylation and expression was also studied by treating with zebularine, and by RNA interference and CRISPR/Cas9-mediated gene knockout. The implications of these results for the potential application of RPRM as a biomarker and DNMT inhibitionbased therapeutics are discussed.

\section{RESULTS}

\section{Cancer-related $\boldsymbol{R} P \boldsymbol{R} M$ promoter methylation in gastric cancer}

The location of $\mathrm{CpG}$ islands in the 5'-flanking region of $R P R M$ gene was predicted by MethPrimer [4] and we picked a pair of bisulfite sequencing primers which span the $261 \mathrm{bp}$ region containing $30 \mathrm{CpG}$ sites (Figure 1). The methylation profiles of various tissue samples from
60 gastric cancer patients were studied by bisulfite sequencing and methylation-sensitive melt curve analysis (MS-MCA). The methylation in the RPRM promoter region occurred in $75.0 \%(45 / 60)$ of the primary human gastric cancer tissues, but only in $43.5 \%(20 / 46)$ of the corresponding adjacent normal tissues. A high occurrence of methylation $(86.3 \%, 44 / 51)$ was also found in the plasma samples of the gastric cancer patients, but rarely found in plasma $(7.9 \%, 3.38)$ or in PBMC samples $(2.4 \%$, $1 / 49$ ) of healthy adults (Table 1). The RPRM methylation was also found in all of the 2 gastric cancer cell lines, BGC-823 and AGS, but not in the gastric epitheliumimmortalized cell line GES-1 (Figure 1).

\section{Transcriptional silencing by $R P R M$ promoter methylation}

To better understand the mechanism involved in the $R P R M$ expression, we studied the relationship between the $R P R M$ promoter methylation and its expression. To ask if the RPRM methylation resulted in transcriptional silencing of $R P R M$ in gastric cancer, the mRNA expression level was evaluated by RT-PCR in the above four cancercell lines. The RPRM methylation statuses of these samples were also indicated according to the bisulfite sequencing results (Figure 1). In anticorrelation with the $R P R M$ promoter methylation, the $R P R M$ mRNA expression was almost undetectable in two of four cancer cell lines. In contrast, we found weak $R P R M$ mRNA expression in the SGC-7901 cell line and strong RPRM mRNA expression in the GES-1 cell line (Figure 2). Thus, the RPRM mRNA transcription was inversely correlated with the $R P R M$ methylation.

\section{Zebularine restores the RPRM expression by inhibiting DNA methylation}

Previous studies have shown that hypermethylation of the promoter region is one of the principal mechanisms to silence the RPRM expression [4, 38]. To investigate the effects of DNA methylation on gene expression, we selected a demethylating drug, zebularine, and examined its ability to affect the $R P R M$ expression in the AGS and SGC-7901 cells. Its effects on cell viability were first assessed by MTT assays to determine the optimal concentrations of zebularine used for the following studies. For AGS cells, the cell viability was reduced more than $50 \%$ after $96 \mathrm{~h}$ treatment with $50 \mu \mathrm{M}$ zebularine, while for SGC-7901 cells, the cell viability was reduced to $50 \%$ after $72 \mathrm{~h}$ treatment with $12.5 \mu \mathrm{M}$ zebularine (Figure 3). Thus, AGS cells appeared to have a stronger tolerance relative to SGC-7901 cells.

Next, AGS and SGC-7901 cells were treated with the different concentrations of zebularine to test its demethylating effects on the RPRM gene. The bisulfite sequencing results showed that the percentage of the 
RPRM gene methylation was reduced after zebularine treatments in both AGS and SGC-7901 cells (Figure 4).

Simultaneously, zebularine's effects on the $R P R M$ gene expression at the transcription and translational levels in AGS and SGC-7901 cells were also assessed. As shown in Figure 4B and C, zebularine treatments led to an increase of RPRM expression in both AGS and SGC-7901 cells.

We also examined the effects of zebularine on the expression of DNMTs by RT-PCR and Western blotting. Interestingly, zebularine treatments caused a dose-dependent depletion of DNMT1 and DNMT3B proteins, but not DNMT3A in AGS and SGC-7901 cells (Figure 4C). We did not observe the zebularine effect on the mRNA expression of DNMTs (Data not shown). These data indicate that zebularine affects not only DNMT activities as previously reported [27, 39], but also the DNMT expression.

\section{Silencing DNMTS increased the expression of RPRM in two cancer cell lines}

To assess the roles of DNMTs in DNA methylation, we knocked down each of the DNMTs by RNA interference. As shown in Figure 5, the shRNAs significantly inhibited the expression of DNMT1, DNMT3A, and DNMT3B at the mRNA and protein levels. At the same time, knockdown of DNMT1, DNMT3A, DNMT3B, or both DNMT1 and DNMT3B significantly restored the RPRM expression in both AGS and SGC7901 cells (Figure 5B and 5C).

To further validate the effects of DNMTs on the RPRM expression, we used the CRISPR/Cas9 technology to knock out DNMT1, DNMT3A and DNMT3B in AGS cells. We were not able to obtain DNMT1-knockout

A
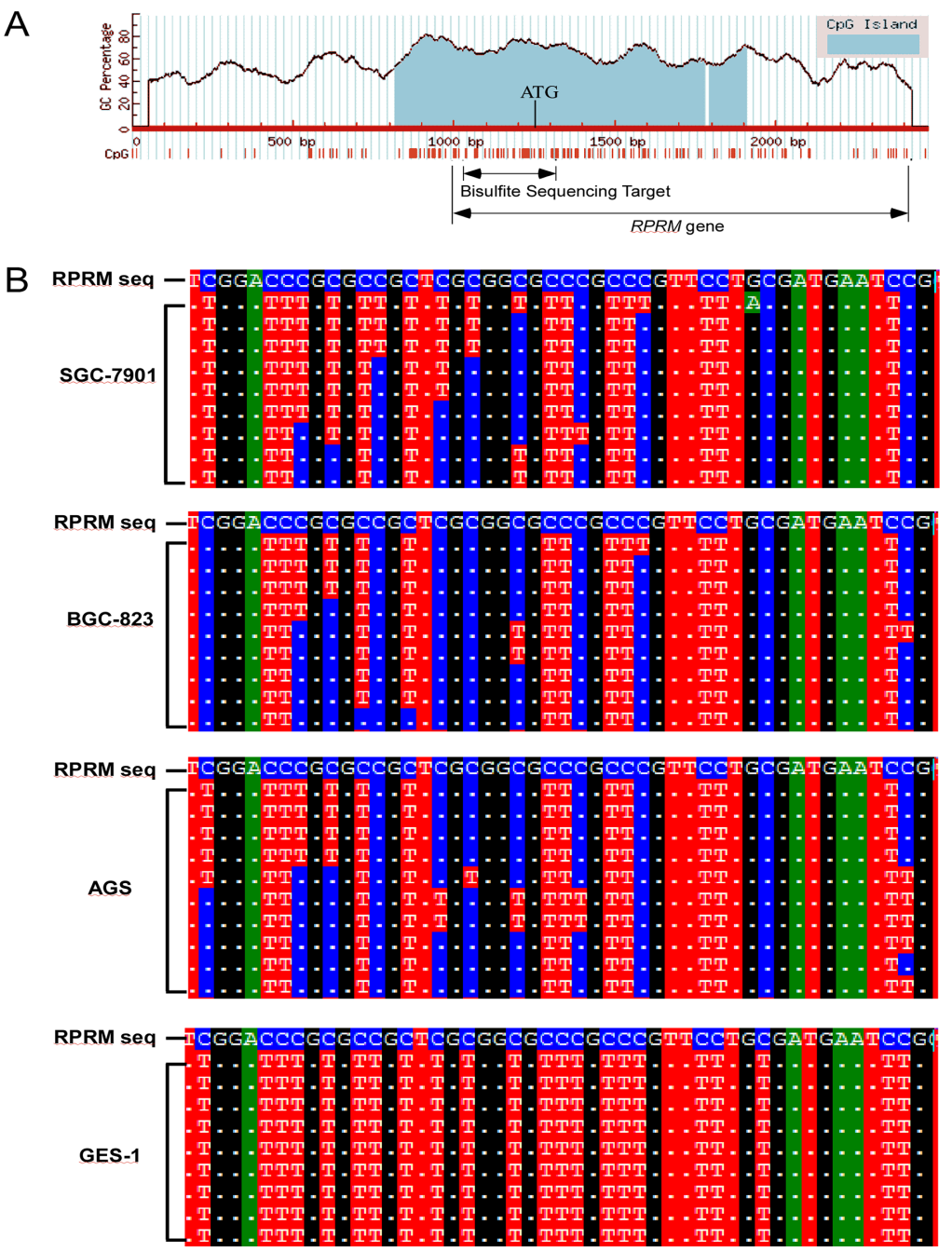

Figure 1: The methylation of $\boldsymbol{R} \boldsymbol{P R} \boldsymbol{R}$ promoter region analyzed by bisufite sequencing. (A) The CpG islands of $R P R M$ gene and its 5'-flanking region, predicted by MethPrimer. The RPRM gene, translation initiation sites (ATG), and the bisulfite primers target regions are indicated. (B) RPRM gene promoter bisulfite sequencing results of SGC-7901, BGC-823, AGS and GES-1 cell lines. Only a part of the sequencing results are presented for representation. The RPRM gene reference sequence (RPRM seq) is placed at top of each panel and bisulfite sequencing results of each clones from different cell lines are placed underneath, with unconverted (methylated) cytosine highlighted in blue color. 
Table 1: Methylation of different sample types

\begin{tabular}{lccccc}
\hline \multirow{2}{*}{ Sample Types } & \multicolumn{3}{c}{ Gastric Cancer } & All & Healthy \\
\cline { 2 - 6 } & Ca. Tissues & Para. Tissues & Plasma & PBMC & Plasma \\
\hline Samples & 60 & 46 & 51 & 49 & 38 \\
Methylated & 45 & 20 & 44 & 1 & 3 \\
Met $\%$ & $75.0 \%$ & $43.5 \%$ & $86.3 \%$ & $2.04 \%$ & $7.9 \%$ \\
\hline
\end{tabular}

cell clones due to the extensive cell death induced by DNMT1 knockout. But several DNMT3A and DNMT3Bknockout cell clones were selected and confirmed by sequencing verification (Figure 6). Knocking out of DNMT3A or DNMT3B, especially the latter one, resulted in a significant increase of the RPRM mRNA by decreasing the RPRM promoter methylation as shown by qRT-PCR analyses (Figure 6). These data suggest an inverse correlation between DNMT functions and RPRM expression.

\section{RPRM is localized in the cytoplasm and its expression can be recovered by DNMT gene silencing}

To further confirm the effects of DNMTs on the RPRM expression, we performed the immunofluorescent analyses by confocal microscopy in SGC-7901 cells transfected with the corresponding shRNA constructs and the empty vector, respectively. We observed faint or weak RPRM expression in the cytoplasm of AGS and SGC-7901 cells relative to GES-1 cells. However, the RPRM fluorescent signals were significantly brighter in the SGC-7901 cells transfected with the corresponding shRNA constructs by silencing DNMT3A, DNMT3B or both DNMT1 and DNMT3B (Figure 7), an outcome that is consistent with our Western blotting results.

\section{Loss of RPRM promoted the tumor formation.}

We next explored the role of RPRM in tumorigenesis in mice. We successfully generated the RPRM-deficient SGC-7901 and BGC-823 cell lines using the CRISPR/ Cas9 technology (Figure 8A). The RPRM gene deficient SGC-7901 and BGC-823 cells were then subcutaneously inoculated onto the right shoulders of female BALB/ cAJcl nude mice. The effect of the loss of RPRM on tumor formation was observed 10 days after inoculation. We found that 3 out of 5 mice displayed tumors arising from the RPRM-deficient SGC-7901 cells while 1 out of 5 mice had tumors arising from the control SGC-7901 cells (Figure 8B). Three out of 5 mice displayed tumors with both the RPRM-deficient and control BGC-823 cells (Figure 8C). However, the volume in all tumors inoculated with Reprimo-deficient cell lines were larger than those in the mice inoculated with counterpart control cells. These data suggest that the loss of RPRM can enhance tumor formation, which is consistent with its role functioning as a tumor suppressor.

\section{DISCUSSION}

We used bisulfite sequencing and MS-MCA to evaluate the methylation status of the RPRM promoter in the tumor and para-cancerous tissues, and plasma
A

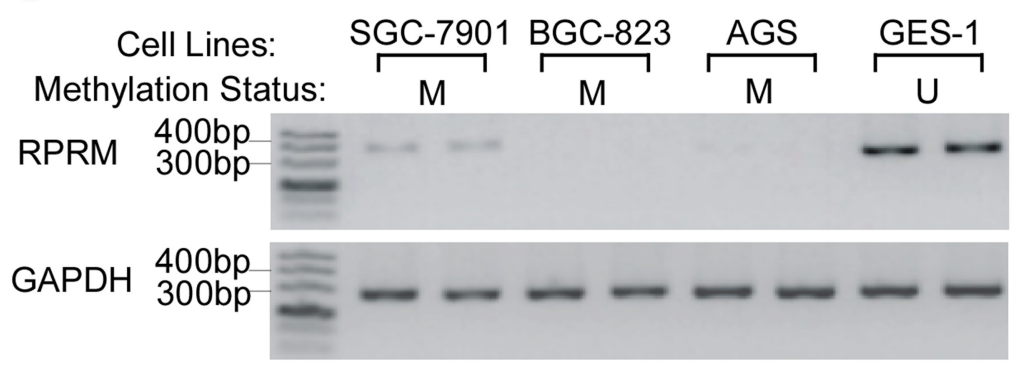

B

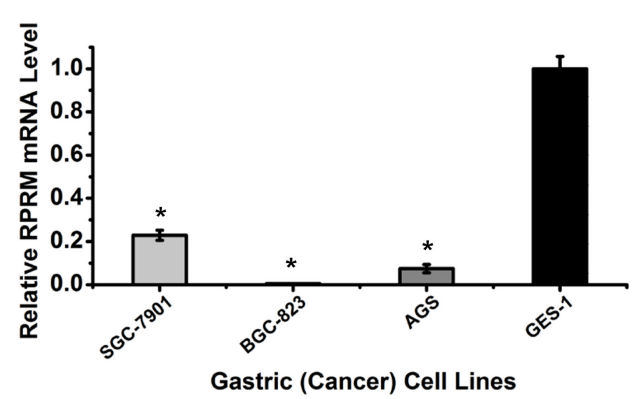

Figure 2: The RPRM mRNA expression in four cell lines. (A) The mRNA transcription levels of RPRM in SGC-7901, BGC-823, AGS and GES-1 cell lines analyzed by RT-PCR. M, refers to methylated status of the RPRM promoter; U, refers to unmethylated status of the RPRM promoter. The levels of RPRM mRNAs in SGC-7901, BGC-823, AGS cell lines are low relative to that in the GES-1 cell line. (B) The statistical presentation of A. The mRNA transcription level is analyzed by densitometry using NIH Image J software and the fold changes of the mRNA expression is normalized to the GAPDH control. The data are analyzed by Student's-t test and presented as mean \pm $\mathrm{SD}\left(n=3,{ }^{*} p<0.05\right)$. 
samples of gastric cancer patients and normal healthy individuals. Consistent with our methylation-sensitive melt curve analyses [40], the $R P R M$ promoter methylation was detected in all of the tumor tissues of gastric cancer patients. However, for some para-cancerous tissues,
$R P R M$ was also methylated, which suggests that the cellular fate of the para-cancerous tissues may have been changed or transformed, which is consistent with previous observations [4]. In agreement with the previous observations $[41,42]$, our data also show the
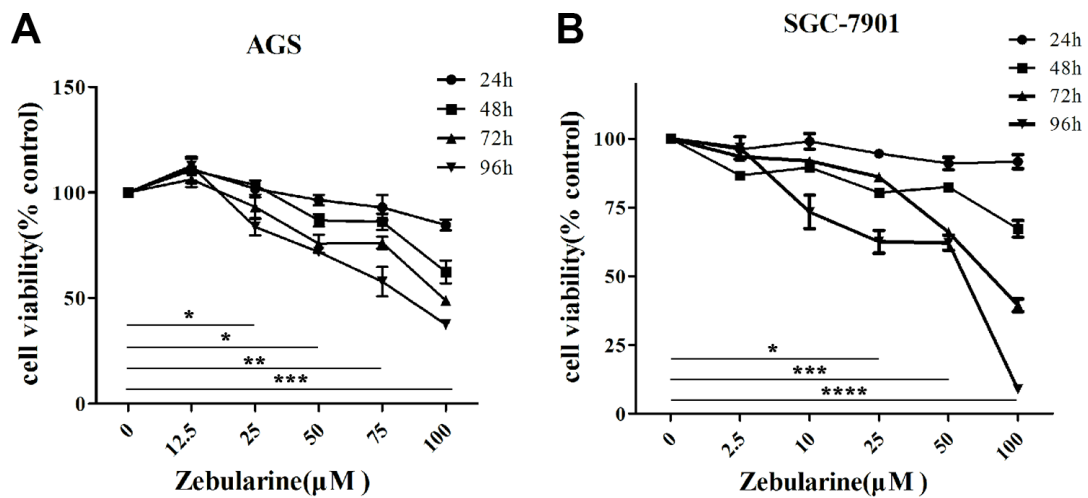

Figure 3: The effects on cell viability by zebularine in the designated doses and time points. AGS (A) and SGC-7901 (B) cells were treated with different doses of zebularine for 24, 48, 72 and $96 \mathrm{~h}$, and measured by the MTT assay, respectively. SGC-7901 cells appear to be more sensitive to zebularine treatments. The above experiments were repeated at least 6 times. The data of 96 hour treatments were analyzed by Student's-t test and presented as mean changes $\pm \operatorname{SD}\left(n=6,{ }^{*} p<0.05,{ }^{* *} p<0.01,{ }^{* * *} p<0.001,{ }^{* * * *} p<0.0001\right)$.

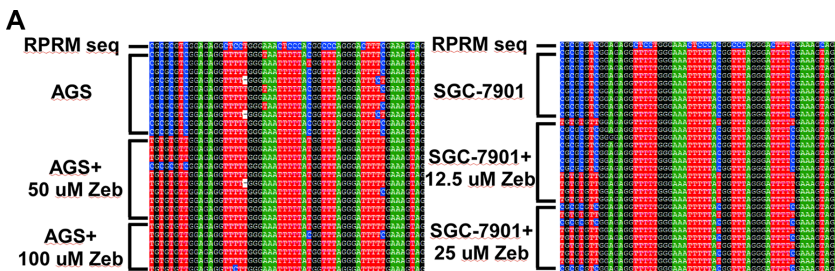

B

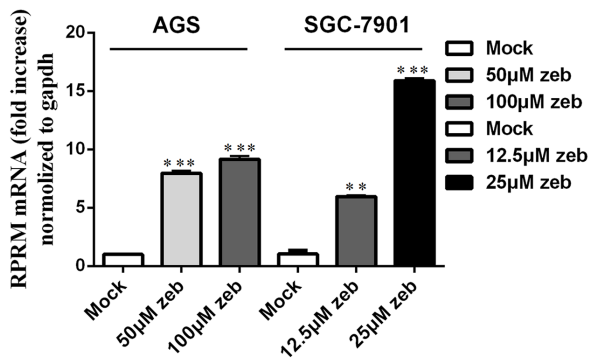

C

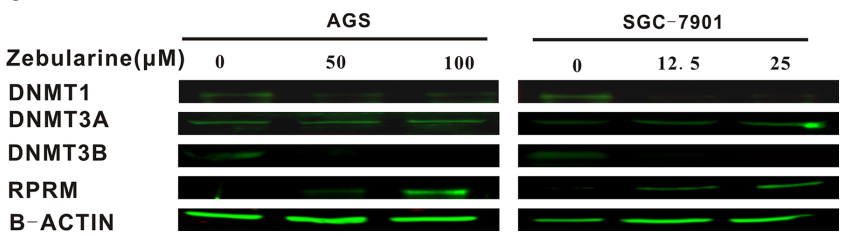

Figure 4: Demethylation effects of zebularine and its impact on the mRNA and protein expression of RPRM and DNMTs. (A) The methylation of RPRM promoter region was analyzed by bisulfite sequencing in AGS cells treated with $50 \mu \mathrm{M}$ and 100 $\mu \mathrm{M}$ zebularine for $96 \mathrm{~h}$, respectively; and SGC-7901 cells treated with $12.5 \mu \mathrm{M}$ and $25 \mu \mathrm{M}$ zebularine for $96 \mathrm{~h}$, respectively. The blue C denotes methylated CpG sites. (B) The mRNA transcription levels of DNMT1, DNMT3B and RPRM after treatment with zebularine at the designated doses, and analyzed by qRT-PCR in AGS and SGC-7901 cell lines, respectively. The fold changes of RPRM mRNA expression are normalized to the internal GAPDH control. The statistical analyses are performed by Student's- $t$ test and the data are presented as mean $\pm \mathrm{SD}\left(n=3,{ }^{* *} p<0.01,{ }^{* * *} p<0.001\right)$. (C) The protein expression levels of DNMT1, DNMT3A, DNMT3B and RPRM in SGC-7901 and AGS cell lines after treatment with zebularine at the designated doses and analyzed by Western blotting. 
$R P R M$ hypermethylation in the plasma of gastric cancer patients in contrast to the plasma of control subjects. Thus, the aberrant RPRM promoter methylation may be manifested by using the gastric cancer patients' plasma samples. The RPRM hypermethylation has been reported in premalignant conditions such as Barrett's esophagus [43] and non-malignant gastric epithelia [1], as well as associated with cagA and vacA s1m1 alleles in the early gastric cancer progression. A role for RPRM in gastric cancer development has been postulated because the loss of RPRM expression was significantly associated with the progression from stage I to stages II-IV of gastric cancer. Therefore, the RPRM methylation may be a useful biomarker for early detection and prognosis of gastric cancer as suggested previously [4].

DNA hypermethylation of tumor suppressor genes is often associated with reduced expression or silencing of tumor suppressor genes. We also examined the correlation between the Reprimo methylation and its expression by RT-PCR in gastric cancer samples (Data not shown). We did not observe a consistent inverse correlation between the Reprimo methylation and its mRNA expression when compared the cancerous samples vs. their corresponding para-cancerous tissues, which is in line with previous report by Maturana et al. [44]. This result may be explained by the following reasons: 1) RT-PCR results might be compromised by the tissue samples, were highly mixed with various cell types including normal and tumorous cells; or 2) the more complex mechanism in addition to methylation may be involved in the regulation of mRNA expression. This question needs to be further addressed in the future. However, in cell lines, we did find that the decrease or loss of RPRM expression is accompanied by the RPRM promoter methylation, in line with previous findings $[4,38,45]$. The promoter methylation and decreased expression of RPRM in gastric cancer is consistent with the role of RPRM as a tumor suppressor gene. Therefore, to increase the RPRM expression and restore its function by demethylation therapy may also be considered for future cancer treatment.
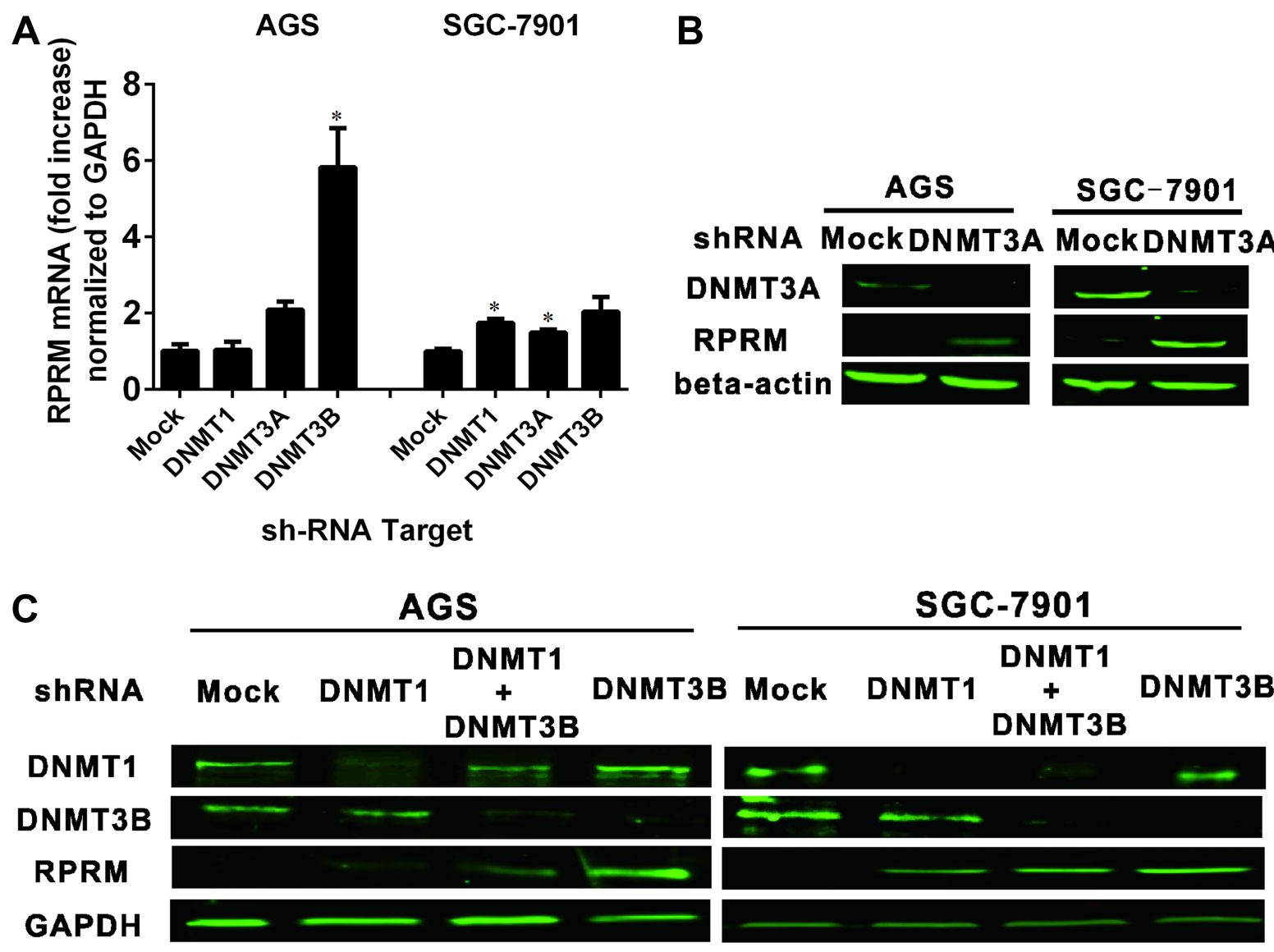

Figure 5: The relationship between DNMTs and RPRM expression evaluated by RNA interference and gene expression. (A) The effects on the RPRM mRNA transcription by RNAi knockdown of DMNTs in AGS and SGC-7901 cells, respectively. The fold changes of the RPRM mRNA transcription were analyzed by qRT-PCR and normalized to the GAPDH control. The statistical analyses are performed by Student's-t test and the data are presented as mean $\pm \mathrm{SD}\left(n=3,{ }^{*} p<0.05\right)$. (B) The protein expression levels of DNMT3A and RPRM in AGS and SGC-7901 cell lines after RNA interference of DNMT3A in AGS and SGC-7901, respectively, and analyzed by Western blotting. (C) The protein expression levels of DNMTs and RPRM after RNA interference of designated DNMTs in AGS and SGC7901 cell lines, resepectively, and analyzed by Western blotting. The RPRM protein $(12 \mathrm{kD})$ is detected at near $38 \mathrm{kD}$ due to its heavy glycosylation[4]. The above qRT-PCR and Western blotting experiments were repeated at least three times. 
In the present study, the RPRM methylation in cancer cell lines was reversed by zebularine, accompanied by partially restored RPRM expression. The DNMT1 and DNMT3B expression, but not DNMT3A expression, were also affected by zebularine in our studies (Figure 4C). However, we did not observe the zebularine effect on the mRNA expression of DNMTs (Data not shown). These data suggest that zebularine does not affect the transcription of DNMTs, but instead may affect the stability of DMNTs. We also found that SGC7901 cells are more sensitive to the zebularine treatment than AGS cells. Therefore, DNMTs are viable targets for DNMT inhibitors, although the sensitivities of these DNMTs may vary in the different cell types and zebularine may function differently in regards with different cancer types. In this context, caution is advised when using these inhibitors in treating different cancers and individuals.

The elevated expression of DNMTs is observed in a variety of malignancies, including gastric, lung, prostate, and colorectal tumors [46-55] and the inhibition of DNMT activity can strongly reduce the formation of tumors [56]. Inhibition of DNMTs correlates with reduction in tumorigenicity and increased expression of tumor suppressor genes [57]; Therefore it has been proposed as
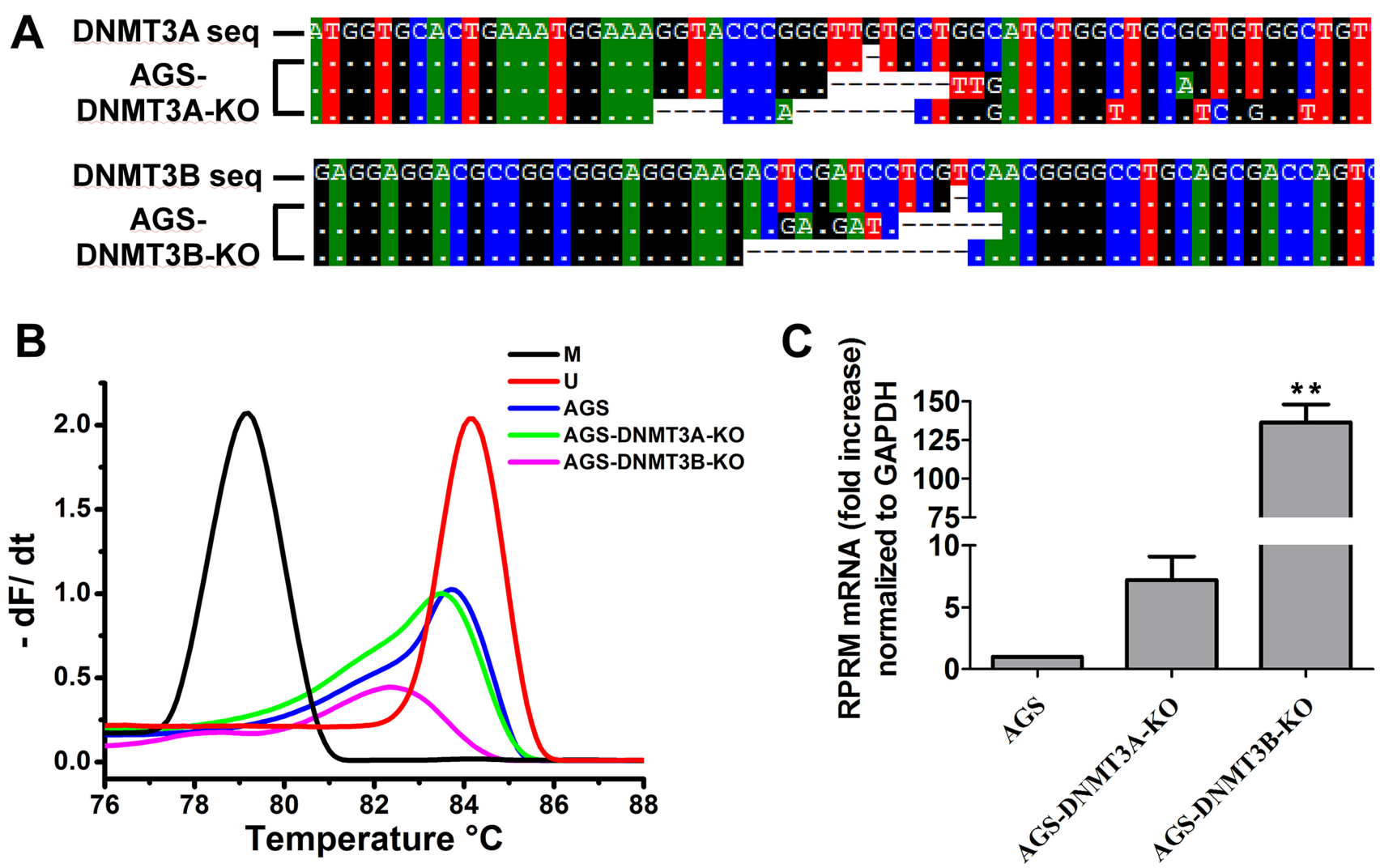

D

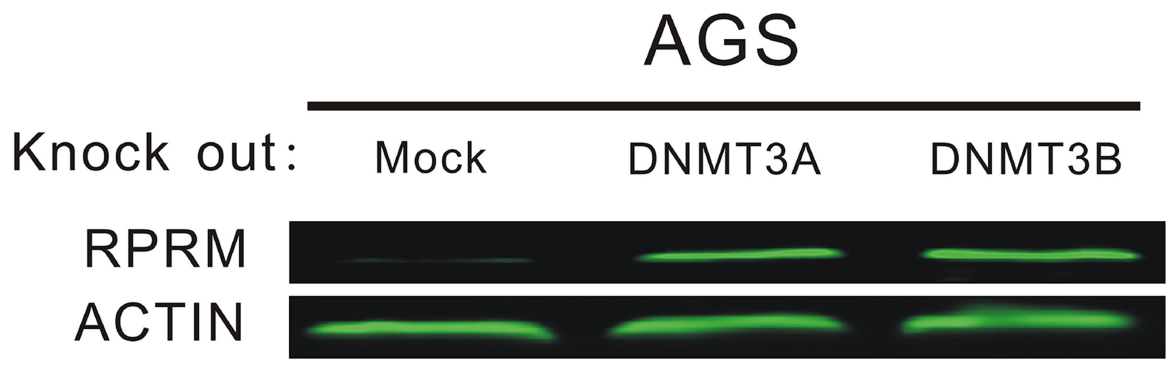

Figure 6: CRISPR/Cas9-mediated DNMT3A or DNMT3B knockout increases the RPRM expression. (A) Verification of DNMT3A and DNMT3B-knockout monoclonal cells by sequencing. (B) The methylation of RPRM promoter region was analyzed by methylation-sensitive melt curve analysis (MS-MCA) as described previously. U indicates the unmethylated melt curve while M represents the melt curve of the full methylated control. Knockout of DNMT3a or DNMT3B causes the methylation-sensitive melt curve to move towards the unmethylated configuration. (C) The qRT-PCR data show that the mRNA transcription level of RPRM is increased by DNMT3A or DNMT3B knockout in the AGS cells. The changes of RPRM mRNA expression are normalized to the internal GAPDH control. The statistical analyses are performed by Student's-t test and the data presented as mean $\pm \operatorname{SD}\left(n=3,{ }^{* *} p<0.01\right)$. (D) The Western blotting data show that the RPRM level is increased by DNMT3A or DNMT3B knockout in the AGS cells. 
a good cancer treatment strategy [9]. To specifically target each of DNMTs, we used RNA interference and knockout strategies. We found that all three DNMTs including DNMT1, DNMT3A and DNMT3B were involved in the $R P R M$ promoter methylation since silencing or knocking out any of above DNMTs was able to affect both methylation and expression of RPRM. These data also suggest that keeping the RPRM gene methylation requires the consonant functions among these DNMTs. These data may be used to explain why the percentage of methylation varied in the different tissue samples, but was not associated with the clinicopathological factors, including age and stage of tumor, as previously reported [4]. These data may also explain why no particular preferably methylated locus or region within the target sequence has been observed by us and others. But it remains unclear what causes the initiation of RPRM methylation.

RPRM has been suggested to be a tumor suppressor, but the direct evidence for this hypothesis is lacking. We showed here that the absence of RPRM was able to enhance tumor formation in mice. These data provided direct evidence regarding the role of RPRM in tumorigenesis and tumor suppression, which is supported by previous studies showing that overexpression of RPRM in gastric cancer cells reduces tumor formation and size [4]. We are currently generating the RPRM genenull mutant mouse to further study the RPRM role in tumorigenesis.

In summary, we confirmed the hypermethylation of $R P R M$ promoter in gastric cancer tissues and plasma. We further studied the relationship of the DNMT inhibitors on $R P R M$ methylation and expression of DNMTs. We found that zebularine reduced the expression of RPRM mRNA and protein in SGC-7901 and AGS cell lines, accompanied by reduced expression of DNMT1 and DNMT3B. Direct inhibition of DNMTs by RNA interference and CRISPR/ Cas9 knockout was also associated with reduction of the expression of RPRM mRNA and protein. The RPRM deficiency can promote tumor formation. These results have an important impact for better understanding the relationship between DNA methylation and RPRM expression, and its role in tumorigenesis.

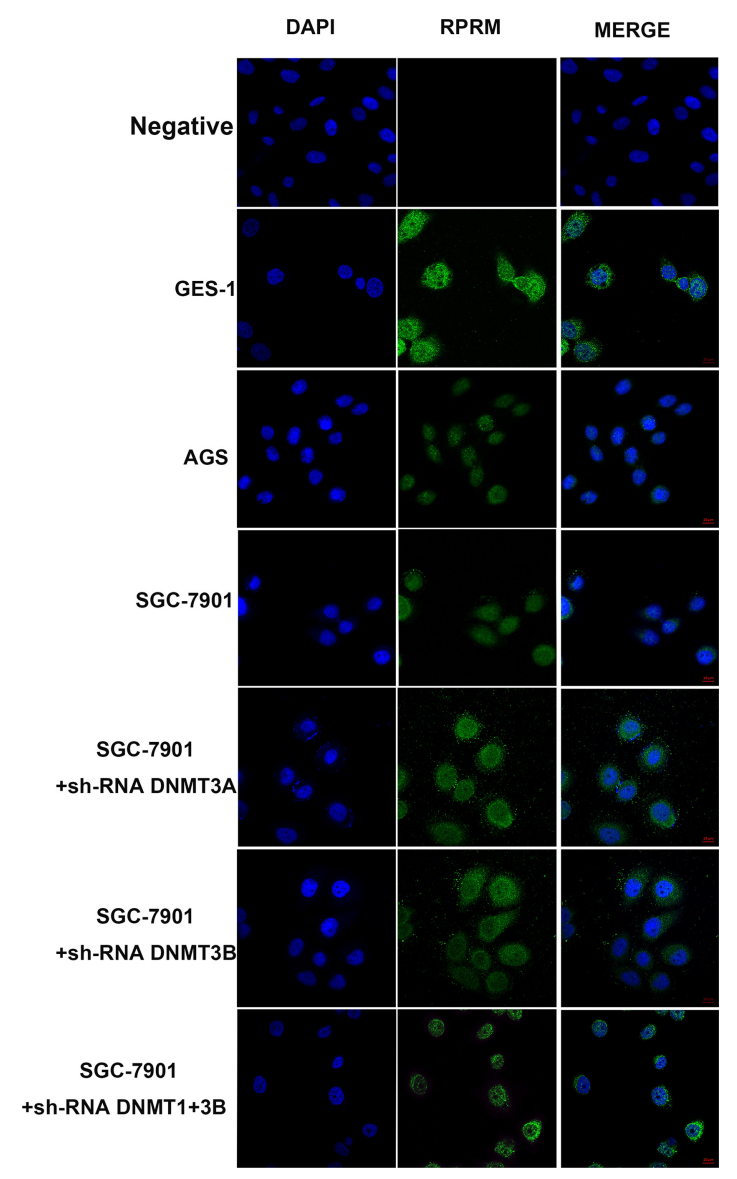

Figure 7: Immunofluorescence analyses of the expression and localization of RPRM in GES-1, AGS, SGC-7901, and SGC-7901 cells after RNAi knockdown of various DNMTs. (A) RPRM is predominantly localized in the cytoplasm. Only faint or weak RPRM protein expression is seen in gastric cancer cell lines AGS and SGC-7901. However, the level of RPRM protein expression is significantly increased in GES-1 and SGC-7901 cells after silencing DNMT3A, DNMT3B and DNMT1+DNMT3B. The absence of primary antibody in the corresponding reaction was served as negative control. Images were taken by the inverted LSM 780/Axio Imager confocal microscope. 


\section{MATERIALS AND METHODS}

\section{Clinical samples and cell culture}

Tissue and blood samples of gastric cancer were collected from the first affiliated hospital of Fujian Medical University following the approval of the hospital's ethics committee and with the signed consent agreements by patients. Totally, 60 clinically-diagnosed gastric cancer patients, 49 healthy adults participated in this project. Among them, 60 gastric cancer biopsy samples taken from gastroscopy and 51 blood samples were collected. As controls, blood samples were also collected from 49 agematched healthy adults without gastric abnormalities and free from malignant tumor invasion. Gastric cancerous and the corresponding para-cancerous tissues were dissected during surgery and stored at liquid nitrogen until DNA extraction. The plasma and peripheral blood mononuclear cells (PBMC) were collected from the above patients or healthy adults by centrifuge at $4,000 \mathrm{rpm}$ and stored at $-80^{\circ} \mathrm{C}$.

The gastric cancer cell lines BGC-823, AGS and human gastric epithelium-immortalized cell line GES-1 or SGC-7901 were obtained from the Shanghai Institute of Digestive Surgery (Shanghai, China) and cultured in an atmosphere of $5 \% \mathrm{CO}_{2}$ in RPMI-1640 medium supplemented with $10 \%$ fetal bovine serum.

\section{Genomic DNA isolation and bisulfite sequencing analyses}

Genomic DNA was extracted by using TaKaRa MiniBEST Universal Genomic DNA Extraction Kit
Ver5.0. DNA was bisulfite converted and purified using EpiTect ${ }^{\circledR}$ Plus Bisulfite Conversion Kit (Qiagen, Germany) according to the manufacturer's instruction.

The above bisulfite-treated DNA was subjected to polymerase chain reaction (PCR). The RPRM primers used for PCR were as follows: 5'-GTTTTAGAAGAGTTTAGTTGTTG-3' (forward) and 5'-CTACTATTAACCAAAAACAAAC-3' (reverse). The PCR products were purified by TaKaRa MiniBEST Agarose Gel DNA Extraction Kit (TAKARA, Dalian, China) and then inserted into a pGEM-T easy vector (Promega, WI, USA). Ten recombinant DNA clones were selected from each sample and sequenced (Sangon Biotech, Shanghai, China). The sequencing results were aligned with the RPRM gene reference sequence (NCBI, NC_000002.12) for determining cytosine methylation using the BioEdit software [58], where the cytosines (C) are highlighted in blue in the alignment results (Figure 1).

\section{Methylation-sensitive melt curve analysis (MS- MCA)}

Methylation-sensitive melt curve analysis (MSMCA) was performed as previously described [40]. Briefly, two control plasmids containing the wild-type and fully $\mathrm{C} \rightarrow \mathrm{T}$ converted $R P R M$ promoter sequences, designated as $\mathrm{SU}$ and $\mathrm{SM}$, were used to generate the unmethylated and fully-methylated melt curve peaks, respectively. The sample DNAs were treated with bisulfite and subjected to real-time PCR by using SYBR ${ }^{\circledR}$ Premix Ex Taq II (Tli RNaseH Plus) (TAKARA, DALIAN, China), and the conditions were as follows: the amplification stage: $95^{\circ} \mathrm{C} 30 \mathrm{~s} ; 95^{\circ} \mathrm{C} 5 \mathrm{~s}, 56^{\circ} \mathrm{C} 15 \mathrm{~s}, 72^{\circ} \mathrm{C}$

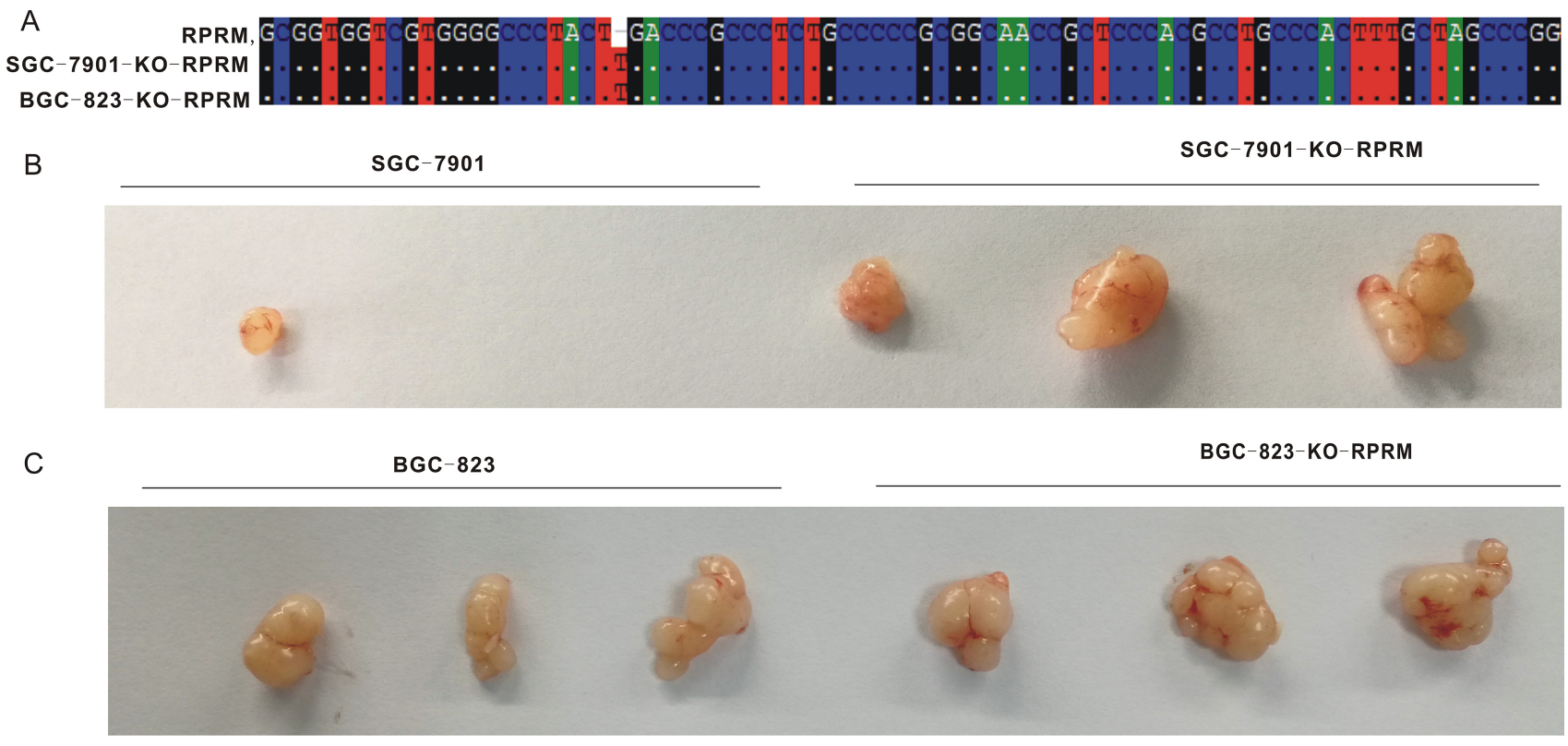

Figure 8: Loss of RPRM promoted tumorigenesis. (A) Verification of SGC-7901 and BGC-823 Reprimo-knockout monoclonal cells by sequencing. (B and C) Tumors formed in nude mice after injected with SGC-7901 and BGC-823 and their reprimo gene knock out cell lines on the right shoulders $\left(1 \times 10^{6}\right.$ cells each injection $)$. 
30 sfor 40 cycles; the melt curve stage: $95^{\circ} \mathrm{C} 15 \mathrm{~s}, 72$ to $88^{\circ} \mathrm{C}$ with $0.1^{\circ} \mathrm{C}$ increment per cycle. The melt curve was generated and used to determine the methylation status of each sample.

\section{RNA isolation and semi-quantitative reverse transcription-PCR}

The total RNA was extracted from gastric cancer tissue samples and cell lines by Trizol (Thermo Fisher Scientific, USA) according to the manufacturer's instruction. The reverse transcription reaction was performed using $1 \mu \mathrm{g}$ of total RNA with PrimeScript $t^{\mathbb{B}}$ RT reagent Kit plus gDNA Eraser (TAKARA, Dalian, China). The following primers were used for PCR: 5'-CTGGCCCTGGGACAAAGAC-3' (forward) and 5'-TCAAAACGGTGTCACGGATGT-3' (reverse) for RPRM; 5'-ACCCACTCCTCCACCTTTG-3' (forward) and 5'-CTCTTGTGCTCTTGCTGGG-3' (reverse) for GAPDH. The PCR was conducted using ExTaq HS DNA polymerase (TAKARA, Dalian, China) under the conditions: $94^{\circ} \mathrm{C}$ denaturation for $5 \mathrm{~min}$, followed by 35 cycles of $94^{\circ} \mathrm{C} 30 \mathrm{~s}, 55^{\circ} \mathrm{C} 30 \mathrm{~s}, 72^{\circ} \mathrm{C} 30 \mathrm{~s}$, then $72^{\circ} \mathrm{C}$ extension for $5 \mathrm{~min}$, finally $4^{\circ} \mathrm{C}$ to terminate the reaction. The PCR products were separated on a $2 \%$ agarose gel.

\section{Real-time RT-PCR}

The mRNA expression levels of DNMT1, DNMT3B and RPRM genes were quantified by the real-time quantitative reverse transcription PCR (qRT-PCR) using SYBR ${ }^{\circledR}$ Premix Ex Taq II (Tli RNaseH Plus) (TAKARA, Dalian, China) at $95^{\circ} \mathrm{C}$ for $30 \mathrm{~s}$, followed by 40 cycles of $95^{\circ} \mathrm{C} 5 \mathrm{~s}, 55^{\circ} \mathrm{C} 30$ $\mathrm{s}$ and $72^{\circ} \mathrm{C} 30 \mathrm{~s}$. The primers used for PCR were as follows: for DNMT1, 5'-GAGGAAGCTGCTAAGGACTAGTTC3'(forward) and 5'-ACTGCACAATTTGATCACTAAATC3'(reverse); for DNMT3B, 5'-TACACAGACGT GTCCAACATGGGC-3' (forward) and 5'-GGATGCCT TCAGGAATCACACCTC-3' (reverse); for RPRM, 5'-CTGGCCCTGGGACAAAGAC-3' (forward) and 5'-TCAAAACGGTGTCACGGATGT-3' (reverse); for GAPDH 5'-CCCTGAGCTGAACGGGAAGCTCAC-3' (forward) and 5'-CTTGCTGTAGCCAAATTCGTTGCT-3' (reverse). The PCR was performed on ABI Step One Plus Fast real-time PCR system (Applied Biosystems, USA), and the changes in expression were calculated by using the $2^{-\triangle \Delta C T}$ method [59].

\section{Cytotoxicity and demethylation tests of zebularine}

AGS or SGC-7901 Cells $\left(5 \times 10^{5}\right.$ cells per T-75 flask) were treated with the various concentrations $(2.5 \mu \mathrm{M}, 12.5$ $\mu \mathrm{M}, 25 \mu \mathrm{M}, 50 \mu \mathrm{M}, 75 \mu \mathrm{M}$ and $100 \mu \mathrm{M})$ of zebularine for $0,24,48,72$ and $96 \mathrm{~h}$. Then, MTT (3-(4,5-dimethyl2-thiazolyl)-2,5-diphenyl-2-H-tetrazolium bromide) assay was performed as previously described [60]. The absorbance was measured by the microplate reader and the cell viability curves were plotted.

AGS cells were treated with $50 \mu \mathrm{M}$ and $100 \mu \mathrm{M}$ of zebularine for $96 \mathrm{~h}$, and SGC-7901 cells with $12.5 \mu \mathrm{M}$ and $25 \mu \mathrm{M}$ for $72 \mathrm{~h}$, respectively. After the treatment, the DNAs were extracted and the RPRM gene methylation was analyzed by bisulfite sequencing.

\section{RNA interference, CRISPR/Cas9-mediated gene knockout, and cell transfection}

RNA interference was performed by transfection of the shRNA plasmid constructs as previously described [61]. The siRNA sequences used for shRNA construction are following: DNMT1: upstream: 5'-GATCCGCAGGCG GCTCAAAGATTTGCTATGGACACAAATCTTTGAG CCGCCTGCTTTTTTTGTCGACA-3'; downstream: 3'-G CGTCCGCCGAGTTTCTAAACGATACCTGTGTTTAG AAACTCGGCGGACGAAAAAAACAGCTGTTCGA-5'; DNMT3A: upstream: 5'-GATCCGCACTGAAATGGAA AGGGTTTTTCAAGAGAAAACCCTTTCCATTTCAG TGCTTTTTTTGTCGACA-3'; downstream: 5'-AGCTT GTCGACAAAAAAAGCACTGAAATGGAAAGGGTT TTCTCTTGAAAAACCCTTTCCATTTCAGTGCG-3'; DNMT3B: upstream: 5'-GATCCAGGTAGGAAAGTAC GTCGCTTCAAGACGGCGACGTACTTTCCTACCTTT TTTTGTCGACA-3'; downstream: 3'-GTCCATCCTTT CATGCAGCGAAGTTCTGCCGCTGCATGAAAGGAT GGAAAAAAACAGCTGTTCGA-5' [62]. The siRNA sequences were inserted into the vector pSilencer2.0-U6hygro (Ambion, USA) followed by cloning and sequencing verification. The resulting plasmids were introduced to AGS cells by transient transfection (see below).

Transfection was done by using Lipofectamine 3000 Reagent (Thermo Fisher Scientific, USA) according to the manufacturer's instruction.

DNMTs gene knockout in AGS cell lines was done by using the CRISPR-Cas9 system [63]. The small guide RNA (sgRNA) sequences used for knock out are as follows: DNMT1, 5'GATGTTGCCGAAGAGCCGGT3'; DNMT3A, 5'GAAAGGTACCCGGGTTGTGC3'; DNMT3B, GAAG ACTCGATCCTCGTCAA; RPRM, 5'GGGCAGAGGG CGGGTCAGTAThe sgRNA sequences were inserted into the vector PX-459 followed by cloning and sequencing verification. The resulting plasmids were used to generate specific DNMT-null AGS cell clones by transfection and antibiotic selection.

\section{Western blot analysis}

Western blotting was performed as previously described [64]. The cells transfected with the various shRNA constructs were washed with ice-cold PBS, harvested by gentle scraping, and lysed with the protein extraction buffer containing $150 \mathrm{mM} \mathrm{NaCl}, 10 \mathrm{mM}$ 
Tris ( $\mathrm{pH}$ 7.2), $5 \mathrm{mM}$ ethylenediaminetetraacetic acid (EDTA), $0.1 \%$ Triton X-100, 5\% glycerol, and 2\% SDS. The samples were electrophoresed on $16 \%$ Tricine-SDSpolyacryomide gels and transferred to polyvinylidene difluoride membranes for hybridization with the corresponding primary antibodies, followed by IRDye $800 \mathrm{CW}$ secondary antibody $(1: 1000)$ and visualized by Odyssey CLx Western Blot Detection System (Westburg, Netherlands). The expression of GAPDH was used as the endogenous control.

\section{Confocal microscopy}

Confocal microscopy was performed as previously described [65]. The cells were transfected by the corresponding shRNA constructs and the empty vector for 48 hours and then selected in the presence of hygromycin ( $1 \mathrm{mg} / \mathrm{ml}$ ) for 5 days. The hygromycin-resistent cells were cultured on the culture chamber slides and used for confocal microscopy analyses. The cells were fixed with $4 \%$ paraformaldehyde plus $0.3 \%$ Triton X-100 in PBS for 20 minutes. Then the cells were incubated with 5\% BSA at room temperature for $30 \mathrm{~min}$. After blocking, the cells were incubated with the rabbit anti-RPRM antibodies (1:200 dilutions) at $37^{\circ} \mathrm{C}$ for $1 \mathrm{~h}$. After washing with PBS for 3 times, each for $10 \mathrm{~min}$, the cells were stained with Alexa Fluor ${ }^{\circledR} 488$ anti-Rabbit $\operatorname{IgG}(\mathrm{H}+\mathrm{L})$ secondary antibody (1:1000 dilutions), followed by DAPI staining. The immunofluorescent images were taken using an inverted LSM 780/Axio Imager confocal microscope (ZEISS, Germany). Fluorophores were sequentially excited at $488 \mathrm{~nm}$ to prevent cross-excitation. The images were collected and raw data were quantified with ZEN120 Imaging Software.

\section{Mouse tumorigenesis assay}

Female BALB/cAJcl nude mice with 6-week-ages were purchased from Shanghai slack laboratory animal Co. LTD. Mice were subcutaneously injected with SGC7901 and BGC-823 and their corresponding reprimo genedeficient cell lines on the right shoulders $\left(1 \times 10^{6}\right.$ cells each injection) (one injection per mouse). Each group consisted of 5 mice. The tumor formation was observed 10 days after inoculation.

\section{Author contributions}

Conceptualization: Qi Chen; methodology: Junzhong Lai, Hanze Wang; validation: Junzhong Lai, Hanze Wang, Qianping Luo, Shanlu Huang, Shujin Lin; formal analysis: Junzhong Lai, Hanze Wang; investigation: Junzhong Lai, Hanze Wang, Yansong Zheng; data curation: Junzhong Lai; writing (original draft preparation): Qi Chen, Junzhong Lai, Hanze Wang; writing (review and editing): Qi Chen, Junzhong Lai, Hanze Wang; visualization: Junzhong Lai, Hanze
Wang. supervision; Qi Chen, Yansong Zheng; project administration: Qi Chen, Yansong Zheng; funding acquisition: Qi Chen, Yansong Zheng.

\section{ACKNOWLEDGMENTS}

We would like to thank the First Affiliated Hospital of Fujian Medical University for providing the clinical samples needed for the study, Shaoli Cai and Zhang Lin for administrative assistance, Dr. Daliang Li and the members of the Chen's laboratory for technical assistance and helpful discussion.

\section{CONFLICTS OF INTEREST}

None.

\section{FUNDING}

This work was supported by Fujian Provincial Health and Education Alliance Funds (WKJ-FJ-28), Fujian Key Laboratories Funds, and Fujian Provincial Lingjun Scholarship to Qi Chen.

\section{REFERENCES}

1. Takahashi T, Suzuki M, Shigematsu H, Shivapurkar N, Echebiri C, Nomura M, Stastny V, Augustus M, Wu CW, Wistuba II. Aberrant methylation of Reprimo in human malignancies. International Journal of Cancer. 2005; 115:503-510.

2. Wang YC, Wei LJ, Liu JT, Li SX, Wang QS. Comparison of Cancer Incidence between China and the USA. Cancer Biology \& Medicine. 2012; 9:128-132.

3. Yan J, Guo X, Xia J, Shan T, Gu C, Liang Z, Zhao W, Jin $\mathrm{S}$. MiR-148a regulates MEG3 in gastric cancer by targeting DNA methyltransferase 1. Medical Oncology. 2014; 31:1-7.

4. Ooki A, Yamashita K, Yamaguchi K, Mondal A, Nishimiya $\mathrm{H}$, Watanabe M. DNA damage-inducible gene, reprimo functions as a tumor suppressor and is suppressed by promoter methylation in gastric cancer. Molecular Cancer Research. 2013; 11:1362-1374.

5. Ohki R, Nemoto J, Murasawa H, Oda E, Inazawa J, Tanaka $\mathrm{N}$, Taniguchi $\mathrm{T}$. Reprimo, a new candidate mediator of the p53-mediated cell cycle arrest at the G2 phase. Journal of Biological Chemistry. 2000; 275:22627-22630.

6. Chik F, Szyf M. Effects of specific DNMT gene depletion on cancer cell transformation and breast cancer cell invasion; toward selective DNMT inhibitors. Carcinogenesis. 2011; 32:224-232.

7. Song B, Jiang A, Kong X, Liu D, Li J. Aberrant DNA Methylation of P16, MGMT, and hMLH1 Genes in Combination with MTHFR C677T Genetic Polymorphism in gastric cancer. Pakistan Journal of Medical Sciences Online. 2013; 29:1338-1343. 
8. Fang JY, Xiao SD. Alteration of DNA methylation in gastrointestinal carcinogenesis. Journal of Gastroenterology \& Hepatology. 2001; 16:960-968.

9. Gore SD, Baylin S, Sugar E, Carraway H, Miller CB, Carducci M, Grever M, Galm O, Dauses T, Karp JE. Combined DNA methyltransferase and histone deacetylase inhibition in the treatment of myeloid neoplasms. Cancer Research. 2006; 66:6361-6369.

10. Lee SH, Kim J, Kim WH, Lee YM. Hypoxic silencing of tumor suppressor RUNX3 by histone modification in gastric cancer cells. Oncogene. 2009; 28:184-194.

11. Jones PA, Baylin SB. The fundamental role of epigenetic events in cancer. Nature Reviews Genetics. 2002; 3:415-428.

12. Robertson KD. DNA methylation, methyltransferases, and cancer. Oncogene. 2001; 20:3139-3155.

13. Denis H, Ndlovu MN, Fuks F. Regulation of mammalian DNA methyltransferases: a route to new mechanisms. Embo Reports. 2011; 12:647-656.

14. Lubecka-Pietruszewska K, Kaufman-Szymczyk A, Stefanska B, Fabianowska-Majewska K. Folic acid enforces DNA methylation-mediated transcriptional silencing of PTEN, APC, RARbeta2 tumour suppressor genes in breast cancer. Biochemical \& Biophysical Research Communications. 2013; 430:623-628.

15. Costello JF. Methylation matters. Journal of Medical Genetics. 2001; 38:285-303.

16. De Andrés MC, Kingham E, Imagawa K, Gonzalez A, Roach HI, Wilson DI, Oreffo ROC. Epigenetic regulation during fetal femur development: DNA methylation matters. Plos One. 2013; 8:e54957.

17. Jurkowska RZ, Jurkowski TP, Jeltsch A. Structure and Function of Mammalian DNA Methyltransferases. Chembiochem. 2011; 12:206-222.

18. Chen C, Pan D, Deng AM, Huang F, Sun BL, Yang RG. DNA methyltransferases 1 and $3 \mathrm{~B}$ are required for hepatitis C virus infection in cell culture. Virology. 2013; 441:57-65.

19. Okano M, Takebayashi S, Okumura K, Li E. Assignment of cytosine-5 DNA methyltransferases Dnmt3a and Dnmt3b to mouse chromosome bands $12 \mathrm{~A} 2-\mathrm{A} 3$ and $2 \mathrm{H} 1$ by in situ hybridization. Cytogenetics \& Cell Genetics. 1999; 86:333-334.

20. Weisenberger DJ, Velicescu M, Cheng JC, Gonzales FA, Liang G, Jones PA. Role of the DNA methyltransferase variant DNMT3b3 in DNA methylation. Molecular Cancer Research Mcr. 2004; 2:62-72.

21. Ksiâa F, Ziadi S, Dhiab MB, Gacem RB, Trimeche M. Increased DNA methyltransferase 1 protein expression correlates significantly with intestinal histological type and gender in gastric carcinomas. Advances in Medical Sciences. 2014; 60:50-57.

22. Pinto A, Zagonel V. 5-Aza-2'-deoxycytidine (Decitabine) and 5-azacytidine in the treatment of acute myeloid leukemias and myelodysplastic syndromes: past, present and future trends. Leukemia. 1993; 7 Suppl 1:51-60.
23. Schwartsmann G, Schunemann H, Gorini CNF, Filho AFF, Garbino C, Sabini G, Muse I, Dileone L, Mans DR. A phase I trial of cisplatin plus decitabine, a new DNA-hypomethylating agent, in patients with advanced solid tumors and a follow-up early phase II evaluation in patients with inoperable non-small cell lung cancer. Investigational New Drugs. 2000; 18:83-91.

24. Gnyszka A, Jastrzebski Z, Flis S. DNA methyltransferase inhibitors and their emerging role in epigenetic therapy of cancer. Anticancer Research. 2013; 33:2989-2996.

25. Cheng JC, Matsen CB, Gonzales FA, Ye W, Greer S, Marquez VE, Jones PA, Selker EU. Inhibition of DNA methylation and reactivation of silenced genes by zebularine. Jnci Journal of the National Cancer Institute. 2003; 95:399-409.

26. Andrade AF, Borges KS, Castrogamero AM, Silveira VS, Suazo VK, Oliveira JC, Moreno DA, Rg DPQ, Scrideli $\mathrm{CA}$, Tone LG. Zebularine induces chemosensitization to methotrexate and efficiently decreases AhR gene methylation in childhood acute lymphoblastic leukemia cells. Anti-cancer Drugs. 2014; 25:72-81.

27. Yoo CB, Cheng JC, Jones PA. Zebularine: a new drug for epigenetic therapy. Biochemical Society Transactions. 2005; 32:910-912.

28. Holleran JL, Parise RA, Joseph E, Eiseman JL, Covey JM, Glaze ER, Lyubimov AV, Chen YF, D'Argenio DZ, Egorin MJ. Plasma pharmacokinetics, oral bioavailability, and interspecies scaling of the DNA methyltransferase inhibitor, zebularine. Clinical Cancer Research. 2005; 11:3862-3868.

29. Beumer J, Joseph E, Egorin MJ, Parker R, D’Argenio D, Covey J, Eiseman J. A mass balance and disposition study of the DNA methyltransferase inhibitor zebularine (NSC 309132) and three of its metabolites in mice. Clinical Cancer Research. 2006; 12:5826-5833.

30. Scott SA, Lakshimikuttysamma A, Sheridan DP, Sanche SE, Geyer CR, Decoteau JF. Zebularine inhibits human acute myeloid leukemia cell growth in vitro in association with p15INK4B demethylation and reexpression. Experimental Hematology. 2007; 35:263-273.

31. Neureiter D, Zopf S, Leu T, Dietze O, Hauser-Kronberger C, Hahn EG, Herold C, Ocker M. Apoptosis, proliferation and differentiation patterns are influenced by Zebularine and SAHA in pancreatic cancer models. Scandinavian Journal of Gastroenterology. 2007; 42:103-116.

32. Billam M, Sobolewski MD, Davidson NE. Effects of a novel DNA methyltransferase inhibitor zebularine on human breast cancer cells. Breast Cancer Research \& Treatment. 2010; 120:581-592.

33. Marquez VE, Kelley JA, Agbaria R, Ben-Kasus T, Cheng JC, Yoo CB, Jones PA. Zebularine: A Unique Molecule for an Epigenetically Based Strategy in Cancer Chemotherapy. Annals of the New York Academy of Sciences. 2005; 1058:246-254.

34. Herranz M, Martíncaballero J, Fraga MF, Ruizcabello J, Flores JM, Desco M, Marquez V, Esteller M. The novel 
DNA methylation inhibitor zebularine is effective against the development of murine T-cell lymphoma. Blood. 2006; 107:1174-1177.

35. Stresemann C, Brueckner B, Musch T, Stopper H, Lyko F. Functional diversity of DNA methyltransferase inhibitors in human cancer cell lines. Cancer Research. 2006; 66:2794 2800.

36. Andersen JB, Factor VM, Marquardt JU, Raggi C, Lee YH, Seo D, Conner EA, Thorgeirsson SS. An integrated genomic and epigenomic approach predicts therapeutic response to zebularine in human liver cancer. Science Translational Medicine. 2010; 2:3571-3589.

37. Hurd PJ, Whitmarsh AJ, Baldwin GS, Kelly SM, Waltho JP, Price NC, Connolly BA, Hornby DP. Mechanism-based inhibition of C5-cytosine DNA methyltransferases by 2-H pyrimidinone 1. Journal of Molecular Biology. 1999; 286:389-401.

38. Saavedra K, Valbuena J, Olivares W, Marchant MJ, Rodríguez A, Torresestay V, Carrascoavino G, Guzmán L, Aguayo F, Roa JC. Loss of Expression of Reprimo, a p53induced Cell Cycle Arrest Gene, Correlates with Invasive Stage of Tumor Progression and p73 Expression in Gastric Cancer. Plos One. 2015; 10:e0125834.

39. Cheng JC, Yoo CB, Weisenberger DJ, Chuang J, Wozniak C, Liang G, Marquez VE, Greer S, Orntoft TF, Thykjaer T. Preferential response of cancer cells to zebularine. Cancer Cell. 2004; 6:151-158.

40. Wang H, Zheng Y, Lai J, Luo Q, Ke H, Chen Q. Methylation-Sensitive Melt Curve Analysis of the Reprimo Gene Methylation in Gastric Cancer. Plos One. 2016; 11:e0168635.

41. Tang N, Frank A, Kowal R, Leckie G, Jr JH, Simmons G, Busch M, Abravaya K. Reprimo as a potential biomarker for early detection in gastric cancer. Clinical Cancer Research. 2008; 14:6264.

42. Liu L, Yang X. Implication of Reprimo and hMLH1 gene methylation in early diagnosis of gastric carcinoma. International Journal of Clinical \& Experimental Pathology. 2015; 8:14977.

43. Hamilton JP, Sato F, Jin Z, Greenwald BD, Ito T, Mori Y, Paun BC, Kan T, Cheng Y, Wang S, Yang J, Abraham JM, Meltzer SJ. Reprimo methylation is a potential biomarker of Barrett's-Associated esophageal neoplastic progression. Clinical Cancer Research. 2006;12:6637-6642.

44. Maturana MJ, Garrido M, Medina L, Slako M, Funke R, Acevedo F, Giraldo C, Sanchez M, Munoz C, Corvalan A. A novel potential biomarker to monitor treatment response in gastric cancer. 2012; 17:231-236.

45. Luo J, Zhu Y, Yang G, Gong L, Wang B, Liu H. Loss of Reprimo and S100A2 expression in human gastric adenocarcinoma. Diagn Cytopathol. 2011; 3:752-7.

46. Manoharan M, Ramachandran K, Soloway MS, Singal R. Epigenetic targets in the diagnosis and treatment of prostate cancer. International Braz J Urol. 2007; 8:368-370.
47. Lin RK, Hsu HS, Chang JW, Chen CY, Chen JT, Wang YC. Alteration of DNA methyltransferases contributes to $5^{\prime} \mathrm{CpG}$ methylation and poor prognosis in lung cancer. Lung Cancer. 2007; 55:205-13.

48. Eads CA, Danenberg KD, Kawakami K, Saltz LB, Danenberg PV, Laird PW. CpG island hypermethylation in human colorectal tumors is not associated with DNA methyltransferase overexpression. Cancer Research. 1999; 59:2302-2306.

49. Eldeiry WS, Nelkin BD, Celano P, Yen RW, Falco JP, Hamilton SR, Baylin SB. High expression of the DNA methyltransferase gene characterizes human neoplastic cells and progression stages of colon cancer. Proceedings of the National Academy of Sciences of the United States of America. 1991; 88:3470-3474.

50. Patra SK, Patra A, Zhao H, Dahiya R. DNA methyltransferase and demethylase in human prostate cancer. Molecular Carcinogenesis. 2002; 33:163-171.

51. Girault I, Tozlu S, Lidereau R, Bièche I. Expression Analysis of DNA Methyltransferases 1, 3A, and 3B in Sporadic Breast Carcinomas. Clinical Cancer Research. 2003; 9:4415-4422.

52. Oh BK, Kim H, Park HJ, Shim YH, Choi J, Park C, Park YN. DNA methyltransferase expression and DNA methylation in human hepatocellular carcinoma and their clinicopathological correlation. International Journal of Molecular Medicine. 2007; 20:65-73.

53. Warnecke P. Increased DNA methyltransferase expression in leukaemia. Leukemia. 1998; 12:311-316.

54. Qu Y, Mu G, Wu Y, Dai X, Zhou F, Xu X, Wang Y, Wei F. Overexpression of DNA methyltransferases 1, 3a, and 3b significantly correlates with retinoblastoma tumorigenesis. American Journal of Clinical Pathology. 2010; 134:826-834.

55. Amara K, Ziadi S, Hachana M, Soltani N, Korbi S, Trimeche M. DNA methyltransferase DNMT3b protein overexpression as a prognostic factor in patients with diffuse large B-cell lymphomas. Cancer Science. 2010; 101:1722-1730.

56. Gravina GL, Festuccia C, Marampon F, Popov VM, Pestell RG, Zani BM, Tombolini V. Biological rationale for the use of DNA methyltransferase inhibitors as new strategy for modulation of tumor response to chemotherapy and radiation. Molecular Cancer. 2010; 9:259-268.

57. Suzuki T, Miyata N. Non-hydroxamate histone deacetylase inhibitors. Current Medicinal Chemistry. 2005; 12:28672880.

58. Hall TA. BioEdit: a user-friendly biological sequence alignment editor and analysis program for Windows 95/98/ NT. Nucl Acids Symp Ser. 1999; pp. 95-98.

59. Livak KJ, Schmittgen TD. Analysis of Relative Gene Expression Data Using Real-Time Quantitative PCR and the $2-\Delta \Delta$ C T Method. Methods. 2001; 25:402-408.

60. Hahm HA, Dunn VR, Butash KA, Deveraux WL, Woster PM, Jr CR, Davidson NE. Combination of standard 
cytotoxic agents with polyamine analogues in the treatment of breast cancer cell lines. Clinical Cancer Research. 2001; 7:391-399.

61. Chen Q, Chen TJ, Letourneau PC, Costa LDF, Schubert D. Modifier of cell adhesion regulates $\mathrm{N}$-cadherin-mediated cell-cell adhesion and neurite outgrowth. The Journal of Neuroscience. 2005; 25:281-290.

62. Zhang S, Zeng F, Peng S, Zhu C, Li H, Wang L. Effects on biological behavior of bladder carcinoma T24 cells via silencing DNMT1 and/or DNMT3b with shRNA in vitro. Journal of Huazhong University of Science and Technology Medical sciences. 2009; 29:215-219.
63. Horvath P, Barrangou R. CRISPR/Cas, the immune system of bacteria and archaea. Science. 2010; 327:167-170.

64. Chen Q, Kimura H, Schubert D. A novel mechanism for the regulation of amyloid precursor protein metabolism. The Journal of Cell Biology. 2002; 158:79-89.

65. Chen Q, Peto CA, Shelton GD, Mizisin A, Sawchenko PE, Schubert D. Loss of modifier of cell adhesion reveals a pathway leading to axonal degeneration. The Journal of Neuroscience. 2009; 29:118-130. 